such as the World Veterinary Association, the Office International des Epizooties and the Food and Agriculture Organization of the United Nations. The Ministry's Animal Health Division has played an important part in building up and supporting such bodies, the importance of which has grown with the enormous increase in inter. national traffic in livestock and their products and with the need to devote ever increasing attention to animal disease problems of developing countries in the war against want. To such countries in particular the final chapter dealing with the principles and practice of preventive medicine will be of special significance.

A. Robertson

\section{NEW INTERNATIONAL REFERENCE ATMOSPHERE}

\section{CIRA 1965}

Cospar International Reference Atmosphere 1965. Compiled by the Members of Cospar Working Group IV. (Committee on Space Research established by The International Council of Scientific Unions.) Pp. xi +313 (Amsterdam: North-Holland Publishing Company, 1965.) $54 s$.

CINCE the advent of the first artificial satellite in 1957 $\$$ a great deal has been learnt about the Earth's upper atmosphere. On the basis of the earliest results, the Committee on Space Research started work on a reference atmosphere in 1960 and the first tables were published towards the end of the following year under the title CIRA 1961. Over the next few yoars many new results were obtained for different levels of solar activity. A new set of tables has, therefore, been compiled by members of Cospar Working Group IV, and is known as CIRA 1965, although much of the tabulation was complete by May 1964 .

The reference atmosphere is presented in three parts, each of which is preceded by a description of both the observational data and the methods used in the construction of the tables. Part 1 was prepared by K. S. W. Champion and gives the mean atmospheric structure for heights between 30 and $300 \mathrm{~km}$. The maximum and minimum departures of the atmospheric properties from their mean values are also indicated. Part 2 is concerned with the atmospheric structure and its variations in the region from 30 to $80 \mathrm{~km}$. This section was prepared by G. V. Groves using data obtained from a large number of rocket firings; temperature, pressure, density and westto-east wind components are all given as functions of latitude and season.

The largest section, Part 3, was prepared by I. Harris and W. Priester and contains tables of density, temperature, pressure, scale height, mean molecular weight and number densities for heights between 120 and $800 \mathrm{~km}$. This region of the atmosphere is under strong solar control and exhibits several different types of variation. The atmospheric properties are tabulated at two-hourly intervals of local time for ten levels of solar activity, the radiation flux on a wave-length of $10.7 \mathrm{~cm}$ being taken as the index of long-term solar activity. Although the procedure for interpolating the tables to give the atmospheric properties at any particular time appears complicated at first sight, it is not difficult provided one has ready access to geomagnetic indices and solar flux data. There are two deficiencies in Part 3: first, the reference atmosphere applies only to the equatorial and temperate zones of the Earth and, secondly, there is now evidence that the magnitude of the diurnal variation in density is under-estimated in the region below $200 \mathrm{~km}$ for conditions of low solar activity. An additional parameter, which could usefully have boen tabulated in this part, is the density scale height.

Two review papers are included as appendixes. In the first, K. S. W. Champion discusses the structure of the lower thermosphere, which comprises the region between 100 and $200 \mathrm{~km}$. It is a pity that, in an otherwise admirable paper, the author should have perpetuated Izakov's error in believing that King-Hele's values of density can be improved by juggling with values of drag coefficient and density scale height. In the second review, L. G. Jacchia gives an extremely lucid account of the structure and variations of the atmosphere above $200 \mathrm{~km}$. Recent results have shown, however, that he was too pessimistic when discussing the possibilities of evaluating density above $600 \mathrm{~km}$ at solar minimum.

CIRA 1965 reprosents the most detailed tabulation of upper atmospheric properties that has ever been attempted, and Cospar Working Group IV is to be congratulated on the result. The discussion in each part and the two review articles ensure that the reader is fully aware of the limitations in the data which were used to compile the model.

G. E. Cook

\section{LAWYERS AND MONOPOLIES}

\section{Competition and the Law}

By Alex Hunter. (University of Glasgow Social and Economic Studies.) Pp. 328. (London: George Allen and Unwin, Ltd., 1966.) 45s. net.

THE modern British economy, at least in its large private sector, is theoretically one of private enterprises operating in competition. But it has been well known for years that that competition has not been free or unfettered. The period since 1945 has seen significant investigations into the degree of competition, and the increased realization of the limits on competition imposed by the enterprises themselves has provoked Parliamentary attempts, by legal means, to loosen these fotters and to restore greater freedom of competition.

Competition and the Law is an economist's examination of what has become a field of interest to both economists and lawyers, as well as to industry and commerce themselves, and made, moreover, by a scholar who has had personal experience of the systems of investigation and control, having assisted and advised on some of the early cases prepared for the Restrictive Practices Court. It is naturally, therefore, on the economic side that this book is strongest and most interesting; on the legal side it is at times rather shallow and cursory.

The first part comprises throe chapters doaling with the background, the relevant economic theory and the measurement of monopoly power. They bring out the increasing concentration of industry and economic power in Britain, and the steady movement towards mergers which have tended to produce oligopolistic groupings in which the few (Table 1 takes as its basis the three) largest enterprises in given industries have a predominant share in net output and in percentage employment within that industry. Thus in 1958 in the man-made fibres industry the three largest enterprises hed 89 per cont of the net output and 81 per cent of the employment; but equally in three-quarters of industries in that year the three largest enterprises had less than 50 per cent of either net output or of employment. The tendency to oligopoly production in the large-scale process industries is clear, and is even more clear in the cases of some sub-industries such as transmission chains and cotton thread.

The second, and much the longer, part of the book is an examination and criticism of the body of legislation in force in the United Kingdom as at mid-1965. (It is the author's, and the reader's, misfortune that the Monopolies and Mergers Act, 1965, was passed too late to be taken into account in the book.) In discussing the legal doctrines which existed before 1948 (and still exist, so far as not superseded by legislation) there might have been mention of much earlier legislative attempts to grapple with substantially the same problems, such as the Scots Acts 